\title{
RELAÇÕES FEDERATIVAS NO SUS: AUTONOMIA NAS RELAÇÕES INTERGOVERNAMENTAIS DA CIB-SP(*)
}

SUS FEDERATIVE RELATIONSHIPS: AUTONOMY IN THE CIB-SP INTERGOVERNAMENTALS RELATIONSHIPS

Paulo Roberto do Nascimento ${ }^{(* *)}$ Fabiola Zioni ${ }^{(* * *)}$

\section{RESUMO}

O Brasil é uma república federativa e o Sistema Único de Saúde SUS deve se organizar descentralizadamente, com comando único em cada esfera de governo. Há estreita relação entre a descentralização do SUS e a forma federativa de Estado. $O$ federalismo pressupõe autonomia dos entes e o federalismo cooperativo, compartilhamento de atribuições. O SUS contribui para o desenvolvimento da forma de Estado brasileiro, ou seu desenvolvimento é dificultado por este? Para discutir a relação entre a estrutura do SUS e a forma federativa de Estado, analisamos as relações intergovernamentais estabelecidas na Comissão Intergestores Bipartite do Estado de São Paulo. A dimensão administrativa da autonomia foi investigada através do comportamento dos gestores e temas discutidos nas atas das referidas comissões. Optamos por explicitar a discussão realizada em torno das rubricas de transferências federais do SUS. A leitura atenta das atas evidenciou, em primeiro lugar, a existência de um comportamento autônomo por parte dos gestores dos diversos niveis de governo; em segundo, os gestores procuram soluções institucionais para os conflitos, participam da definição do modelo de atenção, o caminho da pactuação quando se trata da distribuição dos recursos financeiros, buscam soluções conjuntas para o processo de

(") Esse artigo apresenta parte das discussões e resultados de estudo mais amplo realizado a título de dissertação de mestrado. Ver NASCIMENTO, 2002.

(**) Sociólogo, mestre em Saúde Pública pela Faculdade de Saúde Pública - USP.

(**) Socióloga, professora doutora da Faculdade de Saúde Pública - USP. 
regionalização da saúde, disposição para o compartilhamento de atribuições. A investigação demonstra a ocorrência dos componentes do federalismo cooperativo e a ausência de fatores restritivos à autonomia formal dos entes federativos.

\section{Palavras-chave}

SUS, Federalismo, Comissões intergestores.

\section{ABSTRACT}

Brazil is a federative republic and the SUS must be organized as a decentralized arrangement, with only one command in each sphere of government. There is a narrow relation between SUS decentralization and the federative form of State. The federalism implies in autonomy of the federative levels and the cooperative federalism implies in sharing attributions. The SUS contributes for the development of the Brazilian State form, or its development is made difficult by that? To argue the relations between the structure of the SUS and the federative form of State we analyzed the intergovernmentals established relationships in the Intermanagers Bipartite Commission of the State of São Paulo. The administrative dimension of the autonomy was investigated through the behavior of the managers and subjects argued in minutes of meeting of the related commissions. We opt to present the discussion concerned to SUS federal transferences headings. The minutes had evidenced independent behavior of the managers of the diverse levels of government, with prominence to: existence of institutionally solved conflicts, participation in the definition of the health attention model, agreement for the distribution of the financial resources, joint brainstorming for the regionalization of the health and willingness to sharing attributions. The inquiry demonstrates the occurrence of the components of the cooperative federalism and no restriction factors to the federative levels formal autonomy.

\section{Keywords}

SUS, Federalism, Intermanagers commissions.

\section{INTRODUÇÃO}

O Sistema Único de Saúde é fruto de um ampla mobilização social e política encabeçada pelo Movimento da Reforma Sanitária. A bibliografia dedicada a descrever esse processo é extensa. ${ }^{(1)}$

(1) Como textos indicativos, citamos: BAPTISTA, 1998; CHIORO, ALMEIDA \& ZIONI; 1997; COHN, 1997; ESCOREL, 1998; HEIMANN et al., 1992. 
O conjunto de diretrizes do SUS configura um sistema de saúde formado por uma rede de serviços públicos e privados descentralizada, com comando único em cada esfera de governo, regionalizada e hierarquizada, na qual o setor privado deve ter uma participação complementar à do setor público, firmada através de convênios e contratos, priorizando-se a participação das instituições filantrópicas e sem fins lucrativos.

Nesse artigo, discutiremos a relação entre a estrutura do SUS e a forma federativa de Estado existente no Brasil, concentrando-nos exclusivamente nas relações intergovernamentais estabelecidas na Comissão Intergestores Bipartite do Estado de São Paulo.(2)

O federalismo no Brasil é marcado pela discussão sobre a indefinição de competências concorrentes dos entes federativos. Kugelmas \& Sola consideram a "indefinição ainda presente do padrão de relações intergovernamentais uma das facetas mais visíveis" do feitio inacabado da "institucionalização democrática no país" (1999, pp. 76 e 77).

Para Almeida (1995), o desenvolvimento histórico dos sistemas federativos produziu situações concretas de federalismos, comportando variadas formas de relações intergovernamentais. Partindo-se do modelo originário norte-americano, formulado sobre um sistema 'não-centralizado', o caminhar concreto dos sistemas políticos acabou por produzir formas federativas de Estado adaptadas a sociedades descentralizadas. A distinção conceitual central nessa formulação provém de Elazar, ${ }^{(3)}$ para quem "Nãocentralização não é o mesmo que descentralização, apesar de esta última ser usada - erroneamente - no seu lugar para descrever sistemas federais. (...) Os sistemas federais clássicos (...) são sistemas não-centralizados. (...), descentralização implica hierarquia - uma pirâmide de governos com o poder fluindo do topo para baixo - ou um centro com uma periferia. (...) A não-centralização é melhor conceitualizada como uma matriz de governos com poderes distribuídos de tal forma que a ordenação dos governos não é fixa". Decorre que sistemas não-centralizados apresentam peculiares relações intergovernamentais, a um só tempo competitivas e cooperativas, cuja interação se dá na base de negociação entre as instâncias de governo.

Continuando, Almeida indica a existência de três tipos básicos de arranjos federativos no que concerne a relações intergovernamentais: do modelo "dual" originário - o primeiro deles - caracteristicamente não-centra-

(2) A CIB-SP foi criada em 1993, seguindo orientação de norma federal (MINISTÉRIO DA SAÚDE, 1993) de que os Estados deveriam constituir instâncias de negociação e decisão quanto aos aspectos operacionais do SUS, entre os gestores governamentais. Há uma comissão bipartite em cada Estado e no plano federal a comissão é tripartite: com representantes governamentais dos municipios, dos Estados e da União.

(3) Apud ALMEIDA, 1995, p. 89. 
lizado, desdobraram-se, de um lado, o "federalismo centralizado", marcado pela forte interferência do governo central nas unidades subnacionais, transformando-os em agentes administrativos daquele, que preserva a "primazia decisória e de recursos". De outro lado, o "federalismo cooperativo", em que há elevada capacidade decisória e de financiamento, próprias das unidades subnacionais, as quais desempenham, em conjunto com o governo central, um amplo leque de atribuições. Assim, da tensão entre primazia de competências comuns e de competências exclusivas emerge a característica fundamental dos federalismos centralizado e cooperativo, o que os aproxima, mais ou menos, de um ideal de relações intergovernamentais de tipo federativo.

Do compartilhamento de competências emerge, portanto, o caráter dos arranjos federativos. Esta formulação, de abrangência genérica, aplica-se particularmente bem ao caso brasileiro, devido ao modelo analítico amplamente empregado nos meios intelectuais para o seu enquadramento no espectro de modalidades federativas. A metáfora "sístole/diástole" é amplamente empregada para se tentar apreender, em um modelo teórico, a renitente alternância histórica de períodos de centralização e descentralização política. O reconhecimento deste movimento pendular sugere certa elasticidade ao sistema federativo brasileiro. Um caso que nunca se aproximou de uma configuração não-centralizada, mas que busca reiteradamente o caminho de consolidação de um sistema federativo cooperativo.

Horta (1999) recupera no Ato das Disposições Constitucionais Transitórias, da Constituição de 1946, o que ele chama de "ensaios embrionários do federalismo cooperativo" no País. Ali, o texto constitucional determinava ao governo federal a incumbência de criar e manter órgãos federais destinados a promover o desenvolvimento de determinadas regiões do País. $O$ desdobramento desse mecanismo constitucional resultou em órgãos notórios, como a Codevasp, Sudam, Sudeco, Sudesul e Sudene. Para o autor, "a competência [federal] para elaborar planos nacionais e regionais de desenvolvimento constitui uma das formas ativas de federalismo cooperativo, inaugurado na Constituição de 1946, em procedimentos fragmentários, para atingir instrumentos de atuação mais consistentes na Constituição de 1988".(4)

Horta, fiel a sua argumentação, acredita que, nos Estados Unidos, desde a década de 1930, o nível de ajuda federal aos Estados levou ao nascimento do federalismo cooperativo, na medida em que foram ultrapassados os "or-

(4) Aqui cabe uma breve advertência sobre a relação conflituosa entre ações cooperativas e preservação da autonomia. BARROSO (1982), mesmo reconhecendo a importância da medida constitucional em despender atenção a regiōes de desenvolvimento problemático, acredita que tal dispositivo feriu a autonomia dos Estados brasileiros: "Muitas das competências que a Constituição retirou dos Estados foram entregues a esses organismos regionais, não por meio da descentralização política, característica da federação, mas mediante descentralização administrativa, o que vem a significar subordinação ao governo central" (p. 47). 
denamentos de justaposição" de competências entre a União e os Estados, característicos do originário federalismo dual. Segundo Rovira, ${ }^{(5)}$ a transformação norte-americana foi ditada por objetivos pragmáticos e deu origem a técnicas de legislação recíproca (os Estados envolvidos ajustam concessões recíprocas), de legislação uniforme (para disciplinar matéria de interesse comum) e, finalmente, de legislação paralela (os Estados envolvidos promulgam simultaneamente uma lei com mesma finalidade e conteúdo).

Ainda recorrendo a Horta, consideremos que o modelo dual norte-americano consagrara uma forma clássica de repartição de competências, atribuindo à União os "poderes enumerados" e aos Estados, os "poderes reservados". ${ }^{(6)}$ Esta fórmula projetou-se no federalismo brasileiro e só veio a sofrer mudanças através da Constituição de 1988, quando se acrescentou ao modelo a "competência comum, de caráter cooperativo, da União, dos Estados, do Distrito Federal e dos Municípios (art. 23, I a XII) e a competência concorrente, de natureza legislativa, da União, dos Estados e do Distrito Federal" (art. 24, I, II, VIII, X, XI e XII) (7) (Horta, 1999; BRASIL, 2000).

O tema da repartição de competências tem implicações imediatas para a pretendida qualificação das relações nas comissões intergestores do SUS. Os entes governativos que ali se fazem representar transportam o peso jurídico de suas competências para o plano das referidas comissões. Some-se a isso um aspecto absolutamente peculiar do processo de descentralização do SUS, encontrável nas Normas Operacionais Básicas (NOBs). Ocorre que na construção legal dos modelos de gestão descentralizada, os referidos instrumentos legais primam por listar funções e atribuições dos gestores, de forma a operacionalizar a implementação do sistema, mediante a identificação de responsabilidades, tanto exclusivas quanto complementares, sem prejuizo da autonomia dos niveis federativos.

Do exposto, cremos que a cultura federativa brasileira, balizada pela configuração constitucional de 1988, exerce forte influência sobre a forma organizativa do SUS, no que se refere à relação entre os gestores, e também na definição e desenvolvimento de suas competências. Assim, a conseqüência imediata, a título de aproximação inicial ao sistema de saúde em implantação, seria a da necessidade de esclarecer o rol de competências dos três entes federativos, os mecanismos vigentes de limitação da imputação de competências e atribuições, e a capacidade efetiva dos entes federa-

(5) Apud HORTA, 1999. Ver referência de ROVIRA, 1986.

(6) Essas figuras jurídicas emergem da Décima Emenda da Constituição norte-americana, incluindo em seu texto: "The powers not delegated to the United States by the Constitution, nor prohibited by it to the States, are reserved to the States respectively, or to the people" (segundo BARROso, 1982, p. 57).

(7) Particularmente importante para nosso estudo, no art. 24 da CF, é o inciso XII: "previdência social, proteção e defesa da saúde". 
tivos no que diz respeito à elaboração de políticas de saúde no âmbito de suas competências.

\subsection{SUS - Descentralização que avança}

No ano de 1990, o sistema de saúde delineado nos preceitos da Carta Constitucional recebe regulamentação através das Leis ns. 8.080/90 e 8.142/ 90. Tão logo regulamentado o SUS constitucional, através das leis orgânicas da saúde de âmbito nacional, passou o Ministério da Saúde, com a participação dos demais níveis de governo, a implementar o sistema emanando as normas operacionais básicas, através de edições sucessivas de detalhamento crescente do processo descentralizador: referentes aos anos de $1991{ }^{\left({ }^{(8)}\right.}$ 1992, 1993 e 1996 (Chioro, Almeida \& Zioni, 1997). Além desses, registre-se o advento, em dezembro de 2000, da Norma Operacional de Assistência à Saúde - NOAS. ${ }^{(9)}$ Todas elas visavam a operacionalizar a descentralização do sistema, delineando, com maior ou menor grau de aprofundamento, atribuições exclusivas e complementares dos gestores.

A idéia de definição de atribuições, aparentemente tão bem delimitadas, exige alguma relativização de nossa parte. Entre a publicação da NOB 01/1996, por exemplo, e a sua implementação, em 1998, Levcovitz, Lima \& Machado (2001) lembram que "o MS publicou uma série de portarias com o objetivo de estabelecer as alterações, as medidas e os parâmetros necessários a sua operacionalização. Essas portarias acabaram por alterar significativamente o conteúdo original da NOB, particularmente no que se refere às formas e aos instrumentos de financiamento específicos nela previstos. Pode-se dizer que a NOB-SUS 01/96 nunca foi integralmente implementada em seu modelo inicial" (p. 279). E continuam: "Além disso, durante o período de sua vigência - 1998 a 2000 - diversas outras portarias também influenciaram o processo de descentralização, ao estabelecerem outras regras com efeitos sobre a descentralização/financiamento/relação entre gestores" (p. 279).

Os autores apontam ainda uma outra ordem de imprecisões quanto às atribuições dos gestores municipais e estaduais que decorrem do próprio texto original da NOB: "a norma dá margem a ambigüidades de interpretação ao apresentar um modelo dicotômico de habilitação, com recorte em um nível de complexidade. Por um lado, em sua parte conceitual, a NOB aponta claramente as responsabilidades do gestor estadual e municipal. Por outro, ao estabelecer o recorte dicotômico de habilitação e ressaltar o

(8) A Norma Operacional Básica de 1991 foi instituída por uma resolução do INAMPS, a partir de solicitação do Ministério da Saúde.

(9) Segundo a Minuta de Instrução Normativa GM/MS, a norma objetiva "definir o processo de regionalização como estratégia de hierarquização dos serviços de saúde e de busca de maior equidade" (art. 19). Foi aprovada em reunião da CIT, em 15.12.2000. 
papel da CIB na decisão sobre o modelo de gestão, propiciou o surgimento de arranjos institucionais e pactos com graus variáveis de descentralização efetiva" (p. 284).

Vale esperar, portanto, que as atribuições assumidas na prática pelos gestores estadual e municipais, em qualquer das formas de gestão previstas, estarão profundamente marcadas pelo processo concreto de implantação do SUS em cada região do País e pela resultante da contenda entre as diversas forças sociais envolvidas na estruturação/desestruturação do sistema.

Longe de investigar as atribuições próprias de cada nível de governo e de cada modalidade de gestão municipal, será mais apropriado partir do fato de que há atribuições, que elas não estão delimitadas linearmente - ou não se prestam a uma apreensão linear sem sofrer profundas distorções na análise - e que a relação entre os gestores é que construirá as atribuições. Construção de um sistema de relações entre gestores, obviamente balizadas por um aparato jurídico-institucional, este sim pactuado e legitimado pelas partes, na medida em que a ele recorrem, ou dele se valem, para a obtenção dos recursos necessários à realização das responsabilidades contraídas com a população e demais forças sociais atuantes.

Entendendo que a expressão mais cristalina de relações federativas é a que se concretiza em atos autônomos dos gestores, a autonomia deve ser entendida como um valor que deve caracterizar todos os entes federativos.

Elemento importante na nossa linha de argumentação provém do entendimento de que ao participarem da elaboração das regras centrais que regeriam a federação, os entes subnacionais legitimam a limitação que impõem a si próprios, como uma autolimitação em prol da união (ou União) dos entes federados. Como estamos tratando de autonomia, apliquemos esse raciocínio à dimensão setorial do SUS. Perguntemos sobre o processo de elaboração da NOB.

Confrontada ao processo de elaboração da NOB 01/93, o da NOB 01/ 96 foi objeto de intensas críticas. ${ }^{(10)}$ Espera-se que o tempo dedicado a sua elaboração tenha servido qualitativamente ao esclarecimento das partes e à acomodação das forças, dada pelo embate, até a sua concretização numa formulação minimamente consensuada. Acredita-se, ainda, que, todos tendo tido a oportunidade de participar do processo, seu resultado final seria uma norma cuja elaboração estaria muito próxima de uma situação de "pacto", verdadeiramente sustentado. Levcovitz, Lima \& Machado (2001) informam que a NOB 01/93 necessitou cerca de seis meses de discussão e negociação para ser elaborada, enquanto para a NOB 01/96 foram necessários 
doze meses. Merhy \& Bueno (1998) falam em dezessete versões preliminares antes da sua publicação, versões estas que poderiam ou teriam desvirtuado as intenções originais. Ressalve-se, ainda, que os mecanismos de indução utilizados pelo MS na vigência da NOB 01/96 constituir-se-ão em um sério fator de limitação da autonomia de Estados e municípios na medida em que venham a ser gestados unilateralmente.

\section{MATERIAL E MÉTODOS}

A dimensão econômica do federalismo é, sem dúvida, um aspecto importante para a compreensão das relações federativas. Entretanto, nesse momento, estaremos nos detendo somente em uma dimensão do fenômeno, dimensão esta denominada administrativa da autonomia dos entes federativos. Assim procedendo, estaremos adotando sugestão de Medici (2001), que, ao estudar a atenção à saúde no caso do federalismo brasileiro, escoIhe fazê-lo através de duas dimensões correlatas: a da autonomia financeira e a da autonomia administrativa. ${ }^{(11)}$

Por autonomia administrativa entendemos o grau de liberdade que os gestores detêm para a tomada de decisões na sua jurisdição, desconsiderados os constrangimentos financeiros. É a dimensão da gestão do sistema, que se refere às responsabilidades de cada ente federativo e, internamente a esses, às atribuições contraídas pelo gestor em função da sua forma de inserção no SUS, ou seja, a modalidade de gestão do SUS que assumiu o município ou o Estado.

Contudo, a proliferação de regras e a possibilidade de definir atribuições, pactuando-as diretamente, criam uma realidade bem diversificada de niveis de gestão e de conjunto de atribuições atinentes às diversas jurisdições. Esse fato pode ser entendido como uma expressão de relações federativas cooperativas, visto que as atribuições não se encontram definidas por repartição de competências exclusivas.

Assim, na medida em que os gestores superam as limitações financeiras, em que questionam as condições de repasse e em que pactuam ações cooperativas, em meio a atribuições partilhadas, as discussões e pactuações realizadas na Comissão Intergestores Bipartite (CIB) indicarão o grau de autonomia das gestões pactuadas.

Para realizar tal verificação, os assuntos tratados nas reuniões foram agrupados, quando possível, em termos das rubricas federais de transferên-

(11) A pesquisa que deu origem a esse artigo incumbiu-se também da dimensão financeira da autonomia. Ver NASCIMENTO (2002), em que poderá ser encontrada ainda uma discussão da autonomia administrativa a partir de assuntos não diretamente relacionados às rubricas federais da Transferência SUS. 
cias de recursos financeiros. Em seguida, o volume de discussão sobre cada rubrica e o grau de aprofundamento técnico e político das discussões foram confrontados com o volume de recursos financeiros correspondente e com a ocorrência de conflito/divergência e de encaminhamento de soluções/convergência pactuadas entre os gestores.

As atas da CIB analisadas compreendem o período entre outubro de

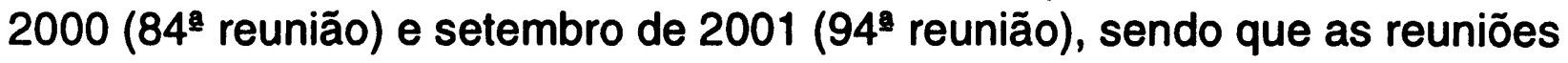
eram mensais. Não ocorreu reunião no mês de janeiro. No mês de junho, houve uma reunião de caráter extraordinário dedicada ao tema do financiamento do sistema. Nessas reuniões, entre membros titulares e suplentes, estiveram presentes cerca de 39 representantes de municipios e Estado, incluindo-se os novos representantes municipais que ingressaram aos quadros do COSEMS, assim como as alterações efetuadas na representação estadual, possivelmente por força das eleições municipais do final do ano 2000.

Quanto aos participantes da reunião, que ali estavam na qualidade de convidados, estes somaram 205 pessoas, distribuídas nas seguintes categorias: participantes provenientes de secretarias municipais de saúde, 131 (de um total de 80 municípios); provenientes de DIR, ${ }^{(12)} 24$ (de 14 DIRs presentes); provenientes dos diversos órgãos da SES ou instituições estaduais, 32 (de 13 órgãos); de instituições federais, 4 (de 3 órgãos); COSEMS, 6 (de 3 instâncias, inclusive do Estado do Rio de Janeiro); e, outras procedências, 5.

\section{RESULTADOS}

Quando iniciamos o processamento das informações contidas nas atas, nossa primeira providência foi agrupar os temas a partir dos pontos de pauta. Isso nos permitiu perceber que geralmente havia vários assuntos reunidos sob um mesmo ponto de pauta. Nossa interpretação foi de que isso, na verdade, decorria do processo de negociação. Cada assunto não é uma realidade completa, autodefinivel, que se esgota em si mesmo. A pactuação pressupõe a busca de um consenso sustentado, que envolve aspectos intrínsecos ao tema, mas que também apresenta facetas atinentes a outros assuntos, ou aspectos cuja percepção conflituosa pode permitir estratégias que levem a avanços em outros temas. Por exemplo, se não há consenso sobre o valor a ser pago pelo Cartão SUS, surge a possibilidade de que se pactue um volume de medicamentos mais próximo do que uma determinada realidade exige. Outra situação possível: se o marketing ministerial está ne-

(12) No Estado de São Paulo, as regiões de saúde são denominadas Diretoria Regional de Saúde (DIR), somando 24 delas. 
gligenciando seu parceiros federativos, abre-se a oportunidade de recolocar em discussão o prazo para cumprimento de determinada tarefa. Enfim, as atas da CIB revelaram uma realidade de saúde muito mais diversificada do que os seus próprios pontos de pauta.

Os dados apresentados a seguir referem-se apenas ao cruzamento entre temas registrados nas atas e a existência de repasse de recursos federais através da modalidade de Transferências SUS, cujos montantes ao Estado de São Paulo, nos anos de 2000 e 2001, encontram-se nos Quadros 1 e 2. Para se ter uma dimensão do recursos envolvidos, registre-se que no ano 2000 o total de recursos federais repassados a título de Transferências SUS a todos os municípios e Estados brasileiros foi de $R \$ 7.573,88$, sendo $\mathrm{R} \$ 4.519,67$ referentes à Assistência Hospitalar e Ambulatorial (MAC), e R\$ 3.054,21 referentes à Atenção Básica.

\subsection{Média e Alta Complexidades}

Entre as rubricas de Assistência Hospitalar e Ambulatorial de Média e Alta Complexidade (a que denominaremos a partir de agora de MAC), observamos que não há registro de discussão quando não ocorre repasse de recursos. Isso aconteceu com os itens Cirurgia de Hérnia, Medicamentos para Transplante, Assistência a Calamidade, Epilepsia, Programa de Pré-Natal e Parto e Terapia Renal Substitutiva (Quadro 1).

Entre as rubricas que sofreram queda no volume de recursos entre 2000 e 2001, não houve discussão das seguintes: Transplantes, Cirurgia de Deformação Crânio-facial, Cirurgia Oncológica, Antígeno HLA, Retinopatia Diabética e Programa de Tuberculose.

Apesar de terem tido aumento de recursos, também não foram discutidas no período: Cirurgia de Próstata, Cirurgia de Catarata e Cirurgia de Varizes.

As Cirurgias Cardiovasculares também não foram discutidas, apesar de pela primeira vez, em 2001, ter havido repasse dessa rubrica. $O$ mesmo ocorreu com a campanha de Acompanhamento de Pós-Transplantados, Campanha de Pré-Natal e MAC para População Indígena.

Note-se que, de fato, não ocorreram discussões sobre temas para os quais não havia recursos previstos, entretanto algumas rubricas que envolviam pequenos montantes, em elevação ou em decréscimo, passaram também ao largo das discussões. Embora a hipótese de relação direta entre registro de discussão e volume de recursos implicados se apresentasse como uma possibilidade explicativa razoável, ocorre que o item Medicamentos Excepcionais, representante do segundo maior montante repassado, tanto em 2000 quanto em 2001 (respectivamente $15 \%$ e 14\% da MAC), não foi também objeto de discussão. 
Por outro lado, algumas rubricas cujo montante repassado se mostrou inexpressivo revelaram-se objeto de discussão. Foi o caso do Programa de Combate ao Câncer de Colo Uterino (cujos recursos diminuíram), Vacinação e Vacinação Anti-Rábica, Impacto de Psiquiatria e Cadastramento e Avaliação de Estabelecimentos de Saúde.

Recursos mais expressivos $(2,5 \%$ do total) receberam os temas de MAC em Vigilância Sanitária, Exames de Carga Viral, CD4 e CD8 e FAEC (Fundo de Ações Estratégicas e Compensação - sob essa designação foram acolhidas as discussões de Radioterapia, Quimioterapia, Radioterapia/ Quimioterapia e Co-financiamento e custeio de unidades próprias). Mas, os dois primeiros foram abordados de forma muito superficial. O FAEC foi objeto de maior atenção.

Assim, a inexistência de recursos coincidiu com a ausência de discussão. Mas alguns temas não foram debatidos, quando envolviam recursos pequenos. Houve, entretanto, discussão de rubricas mínimas e de rubricas com volumes maiores de recursos. Escapa dessa explicação a ausência de discussão sobre Medicamentos Excepcionais, com elevados recursos. Por outro lado, a rubrica genérica Assistência Hospitalar e Ambulatorial de Mac havia consumido $90 \%$ dos recursos e não teve dedicação proporcional nas discussões. Recursos menos substanciais não impediram amplo debate sobre alguns temas.

Para explicitar o teor das discussões, façamos uma breve explanação do tratamento dado ao tema FAEC. ${ }^{(13)}$

Fundo de Ações Estratégicas e Compensação (FAEC) (R\$ 12,47 miIhões de FAEC e R\$ 3,23 milhões de Radioterapia, Quimioterapia e Câmara de Compensação)

O Fundo para Ações Estratégicas e de Compensação entrou em vigor, como rubrica MAC, em 2001, mas já havia repasse a esse título no final de 2000. Já no seu primeiro ano de existência, reuniu recursos consideráveis. $\mathrm{Na}$ CIB-SP, as ações estratégicas foram discutidas em outubro de 2000 e fevereiro, junho, julho e setembro de 2001. A rubrica de Câmara de Compensação foi encaminhada para FAEC e boa parte dos recursos de Radioterapia e Quimioterapia também. Por essa razão, tratamos sob o título FAEC todos esses componentes. O FAEC foi discutido em outubro de 2000, sob o ponto de pauta de Radioterapia. O COSEMS sugeria que os recursos correspondentes - R\$2,3 milhões - fossem distribuídos, pelo critério per ca-

(13) Quando estivermos apresentando as discussões das rubricas, apresentaremos, entre parênteses, ao lado do título de cada item, os recursos financeiros repassados pelo Ministério da Saúde no ano 2001. Além disso, editamos os textos de algumas citações das atas. Com isso, explicitamos quando o texto foi extraído diretamente da ata, mas o apresentamos num formato mais compreensível ao leitor, que não a tem em mãos quando lê este trabalho. 
pita, aos municípios habilitados em qualquer forma de gestão, e que, no âmbito das Comissões Intergestores Regionais (CIRs), deveria ocorrer a pactuação entre os municípios sobre como utilizar os recursos. Mas a Secretaria de Saúde argumentava que o mecanismo fora criado pelo Ministério da Saúde para diminuir os estornos que São Paulo vinha sofrendo em seu teto financeiro. São Paulo vinha tendo estorno entre $R \$ 6$ e 8 milhões por mês, devido às Autorizações de Internação Hospitalar (AlHs) indevidamente encaminhadas e retidas no MS. Para minimizar essa ocorrência, segundo a Secretaria de Estado de Saúde - SP (SES-SP), o MS retirara os recursos do teto estadual e os repassara na forma de FAEC. Como resultado da discussão, pactuou-se que o montante FAEC que correspondesse a recursos estaduais ficaria com o gestor estadual e o correspondente ao município seria rateado da forma proposta pelo COSEMS. Significativas foram as considerações que se seguiram. Por exemplo, o fato de a representação dos municípios lamentar a falta de clareza das contas estaduais, e acrescentar: "Essa portaria é uma luz para os municípios", no sentido que permitirá conhecer ao menos em parte a composição e montante de gastos estaduais.

Entretanto, é lembrada uma outra interpretação dos recursos FAEC, segundo a qual, tratar-se-iam de recursos destinados ao início de um processo de Programação Pactuada Integrada (PPI). Nessa ocasião, um representante municipal teria colocado, como contra-argumento, o fato de que, de acordo com esse raciocínio, os municípios só teriam "dinheiro novo" se o rombo do Estado fosse sanado. Um representante do Estado, por sua vez, retruca que esse rombo proviria das ações do Estado para atender demanda dos municípios, que encaminham doentes para o Hospital das Clínicas de São Paulo, Pérola Byington etc. Lembrava também que, por exemplo, só quem se responsabilizava pela realização das ações de hemodiálise, naquela ocasião, era o Estado. Já, um representante municipal dizia que os municípios controlavam o número de seus atendimentos, coisa que o Estado não fazia. Um representante estadual não vê como poderia 0 Estado "fechar as portas": "O município controla os pacientes e 'joga' para outros municípios ou para o Estado resolver". O representante municipal argumentou então que deveria haver uma Câmara de Compensação para pacientes que provinham de outros Estados e que achava que o maior problema estava na Grande São Paulo, não no interior do Estado. E então, assumindo um tom de resignação ou de ironia, sugeria que, até que algum mecanismo de compensação fosse viabilizado, todo o dinheiro que viesse do Ministério da Saúde, via FAEC, ficasse com o Estado.

Outra evidência de divergência é explicitada em fevereiro: o COSEMS informa que não aceitaria a proposta do Ministério da Saúde de pagar FAEC diretamente ao prestador. $E$ acrescenta que não se sabe o posicionamento do CONASS, mas que o CONASEMS também se posicionara contra.

$\mathrm{Na}$ reunião extraordinária ocorrida em julho de 2001 para discutir financiamento, o tema FAEC é retomado: o representante do Estado informa- 
va que o Ministério da Saúde publicara o teto dos municípios, somando Impacto de Psiquiatria e FAEC. O Estado fizera o mesmo, "corrigindo alguns erros do Ministério, como, por exemplo, o de ter incluído em alguns tetos municipais a gestão estadual".

Em julho e setembro de 2001, o FAEC volta a ser objeto de conflito entre Estado e municípios, conflito este sempre associado ao montante do teto financeiro, às ações de média e alta complexidade ou ao financiamento de unidades hospitalares.

Pareceu-nos, de acordo com esses dados, que as divergências em torno dessa rubrica estão associadas ao fato de ser uma criação recente e por, principalmente, envolver recursos expressivos, frente às demais rubricas. Deve ser remarcado, porém, que seguramente se revestia de uma caracterização incerta: ora era entendida como fonte incipiente de recursos cuja pactuação possibilitaria uma experiência inicial de PPI; ora era tratada apenas como um fundo para compensação dos estornos estaduais de AlHs indevidas; ora, como fundo de financiamento de alta e média complexidade; e, por vezes, era entendida meramente como um artifício de repasse a unidades hospitalares. De fato, em qualquer dessas possibilidades, a disputa pelos recursos revelou alta capacidade conflitiva, cuja explicação teria como base $o$ desconhecimento geral sobre as contas estaduais.

Das 34 rubricas de MAC (25 tiveram repasses de recursos para São Paulo), só encontramos discussão referente a seis delas, sendo que em cinco destas notou-se uma discussão esparsa, escassa. As seis rubricas totalizaram $\mathrm{R} \$ 25,88$ milhões, contra quase $\mathrm{R} \$ 800$ milhões das demais. Sob o tema FAEC, os integrantes da ClB disputaram o terceiro maior volume de recursos repassado mediante rubrica. Ao que parece, 0 interesse pelo tema não se deu pelo volume de recursos, mas pela desestruturação dessa rubrica: recursos com destinação incerta, passíveis de contenda.

A hipótese inicial de que as discussões se concentrariam nas rubricas de maiores recursos não se confirmou. Provavelmente porque esses recursos têm destinação conhecida. Mas o FAEC prestou-se a expectativas diversas: recursos para uma PPI incipiente; montante do teto estadual colocado aos municípios é sinônimo de "dinheiro novo" para estes; oportunidade de cobrar transparência das contas estaduais; possibilidade de se discutir a ascendência do gestor local sobre os prestadores hospitalares. Essas foram as vertentes encontradas na discussão sobre a possível partilha dos recursos "estratégicos".

\subsection{Atenção Básica}

Das rubricas de Atenção Básica, não foram discutidas a de Assistência às Populações Indígenas e Descentralização da FUNASA, para as quais 
não houve repasse de recursos; e Vacinação de Poliomielite, cujos recursos chegaram a quase $R \$ 1$ milhão (Quadro 2). Os demais nove itens (reunimos PACS e PSF sob uma mesmo tema de análise) foram objeto de discussão. Todos eles dispuseram de recursos, em alguns casos, bem superiores aos das rubricas MAC. A seguir apresentamos uma breve descrição de dois deles.

Programa de Incentivo ao Combate das Carências Nutricionais (ICCN) ( $\mathrm{R} \$ 8,96$ milhões)

Sua discussão tomou todo o período estudado. No geral, o tema foi tratado apenas para aprovação de habilitação, apreciação de pedidos de descredenciamento e requalificação. A requalificação é anual. Na reunião de abril de 2001, o MS apontou os municípios atrasados quanto ao envio de sua solicitação.

Em maio de 2001, introduziu-se a discussão do Programa Bolsa Alimentação, do Ministério da Saúde. O SISVAN devia ser mantido e a permanência do município no ICCN era opcional. A transição de um programa a outro deveria ser gradual. Informava-se também que o SISVAN estava implantado em apenas 177 municípios, dos 645 do Estado. Houve resistência porque se tratava de "mais um" cadastro. O COSEMS foi solicitado a veicular matéria que incentivasse os municípios a implantar o sistema.

Em julho de 2001, tem-se prosseguimento do debate sobre o Bolsa Alimentação. Na verdade, o programa chegou fechado aos municípios. A discussão se deu em torno da destinação do cartão magnético, que seria encaminhado pela Caixa Econômica Federal aos serviços de saúde, os quais o encaminhariam à mãe. Os municípios advertiram, na ocasião, que era preciso ter cautela. O Estado entendia o Bolsa Alimentação como um programa mais bem elaborado que seu antecedente. $O$ crivo para a escolha da população alvo seria o "risco nutricional".

Por fim, desenvolveu-se uma discussão sobre o valor - $R \$ 15,00-$ a ser repassado por pessoa cadastrada, até um máximo de três por família, incluindo a nutriz, valor considerado reduzido para a realidade de São Paulo. Esta consideração aplicar-se-ia aos programas ministeriais em geral. Decidiu-se encaminhar um relato da situação à Comissão Intergestores Tripartite.

\section{PSF e PACS (R\$ 57,73 milhões)}

As discussões deram-se principalmente em torno de credenciamento e requalificação. A atenção básica foi tratada com especial cuidado no que diz respeito às condições para a continuidade dos programas. Por exemplo: foram feitas seguidas advertências e lembranças sobre a importância da alimentação dos bancos de dados e encaminhamentos ao Ministério da Saúde 
de pedidos de prorrogação de prazos. Os gestores, como membros da Comissão, representantes dos entes federativos, fizeram registrar em ata, constantemente, a importância do cumprimento dos requisitos necessários à continuidade de recebimento dos recursos dos programas nacionais: preenchimento do Sistema de Informação de Atenção Básica (SIAB), efetivação das metas pactuadas quanto ao cadastramento de usuários, alimentação do SISVAN, cumprimento de prazos para formulação da agenda de saúde, importância da participação das equipes municipais nos eventos de capacitação aos programas.

Temas de grande importância à pactuação entre gestores no Estado passaram a ser tratados a partir da entrada do município de São Paulo nas discussões. Em fevereiro de 2001, a representação do Estado reformulou a solicitação de municipalização dos serviços do município de São Paulo, informando que não se tratava de requalificação, mas de qualificação. A solicitação se tornara necessária pelo reencaminhamento do município a uma forma de gestão do SUS, depois da mudança administrativa decorrente das eleições de 2000. Destacaremos dois temas de alta importância: o Qualis ${ }^{(14)}$ e a municipalização das unidades básicas.

Em setembro de 2001, a discussão sobre o Qualis encontrava-se na seguinte situação: o Estado informara sobre o andamento do trabalho que envolvia a Secretaria de Estado da Saúde e o município de São Paulo para a municipalização e habilitação deste: "A Secretaria de Estado da Saúde e o município se posicionaram quanto ao fato de que o Qualis será o último equipamento a ser municipalizado. O Estado quer acompanhar por mais tempo este projeto. A prefeitura está implantando mais equipes de PSF. $O$ Estado não está ampliando o número de equipes do Qualis. São cerca de 215 equipes. Representante estadual esclarece que, desde a habilitação do Estado à Gestão Avançada, o recurso PAB relativo ao município de São Paulo foi investido na atenção básica do próprio município, através da contratação de equipes e pagamento de equiparação para os funcionários. Representante do município, presente à reunião, concorda que a municipalização de São Paulo se efetivou com a ajuda do secretário, da Diretoria Regional de Saúde I (DIR I) e dos núcleos de saúde. ${ }^{(15)} \mathrm{E}$ acrescenta que, hoje, praticamente todas as unidades estão municipalizadas, querendo que fique registrado o interesse em retomar as negociações quanto à municipalização do Qualis".

Sobre a municipalização das unidades básicas, foi dado o informe, no mês de agosto, de que totalizam 196 unidades e que o processo de munici-

(14) Programa especificamente voltado ao município de São Paulo, destinado à implantação de ações de atenção à saúde da família.

(15) Unidades administrativo-geográficas em que se divide o município de São Paulo, internamente à DIR I. 
palização estava adiantado: havia sido concluído nas regiões dos Núcleos de Saúde 2, 3 e 4, da capital; faltavam quinze unidades na região do Núcleo 5; e estava atrasada na região do Núcleo 1. Mas a expectativa era de que até setembro de 2001 o processo estivesse concluído.

Digno de nota é o registro de uma discussão sobre o valor do Piso Assistencial Básico (PAB) fixo, ocorrida em setembro. O MS havia publicado os novos valores do PAB fixo, calculados a partir dos novos dados populacionais do Censo 2000. Como alguns municípios tiveram diminuição de população, o montante recebido também diminuiria. Representante municipal argumentou que "nestes municípios não ocorreu diminuição das despesas com assistência básica. Portanto propõe-se que a CPS ${ }^{(16)}$ faça um levantamento dos municípios que estão nesta situação, para que seja mantido o recurso anterior. Lembrou também que estes $R \$ 10$ não sofreram nenhum reajuste desde a sua implantação". A proposta foi aprovada e encaminhada ao Ministério.

Ao se tratar do PACS no Estado, boa parte das preocupações provém da forma de incorporação dos agentes aos quadros funcionais, bem como da sua capacitação e integração nas diversas tarefas dos sistemas de saúde.

Sobre o PSF, grande parte da discussão se deu em torno da capacitação dos profissionais, tarefa que os municípios entendiam de responsabilidade precípua do Estado, quanto ao aporte de recursos. Segundo a representação municipal, os municípios vinham gastando recursos muito altos para garantir a capacitação. Esse assunto não vai chegar a ser minimamente resolvido, no período, o que acarretará reincidentes reclamações dos municípios.

Ainda sobre o tema da capacitação, é interessante acompanharmos discussão ocorrida em maio de 2001, sobre o programa Profissionalização dos Trabalhadores na área de Enfermagem (PROFAE): "Representante do Estado informa que em 1999 o MS lançou o Programa de Profissionalização dos Trabalhadores de Enfermagem. Informou também que no mesmo ano não houve participação efetiva dos Estados, o que só começou a partir de 2000. O PROFAE é financiado com recursos do Fundo de Amparo ao Trabalhador (FAT) e do Banco Mundial (BIRD). A SES está participando com 50 turmas de auxiliar de enfermagem e 20 de ensino fundamental. No segundo componente (escolas técnicas), SP está com 4 projetos. Informa que os programas serão mapeados para se saber como estão indo nos municípios e assim verificar a necessidade de mais escolas em regiões carentes. Representante municipal diz que a proposta deve beneficiar os municípios e que recursos humanos são um grande problema para o SUS. Na primeira fase, continua, os municípios não foram envolvidos e os profissionais se cadastraram diretamente no Banco do Brasil. Os cursos eram no horário de traba-

(16) Coordenadoria de Planejamento da Saúde, órgão da SES-SP. 
Iho. Não foi permitida a inscrição de Agentes Comunitários de Saúde. Em SP já não há mais tantos atendentes. Outro representante municipal argumenta que os projetos convergem com a proposta do SUS. Lembra que o Agente Comunitário de Saúde tem uma função específica no PSF e há o risco de que se desvie de seu real papel no programa. O representante municipal que havia se pronunciado anteriormente esclarece que a idéia não é treinar pelo PROFAE todos os Agentes Comunitários de Saúde, mas permitir 0 acesso a todos os profissionais que se interessarem e que o horário permitir. Lembra ainda que mudar de função depende de concurso".

\section{DISCUSSÕES}

Os três temas anteriormente detalhados demonstram a diversidade de proposições e perspectivas apresentadas pelos gestores. Há vários pontos de conflito entre Estado e municípios, entre os dois e o nível federal e há também percepções distintas do mesmo problema entre os municípios.

Note-se também que as rubricas de Atenção Básica suscitaram maior volume de discussão que as de MAC. Uma característica dos debates sobre os temas de Atenção Básica que nos pareceu distintiva em relação às rubricas de média e alta complexidade, e que queremos destacar, é o grau de detalhamento técnico das discussões. É evidente que o volume de recursos de cada uma das rubricas de Atenção Básica é superior, na média, ao volume das rubricas individuais de MAC, mas o teor da discussão das primeiras freqüentemente se deu com uma aproximação técnica das ações, com divergências de parte a parte sobre a qualidade das atividades desempenhadas e preocupação com seus efeitos.

Não descartamos a possibilidade de que esta dedicação ao tema se deva ao volume de recursos envolvidos, mas consideramos a possibilidade de que provenha da sua própria natureza. As ações de Atenção Básica apresentam uma dimensão política e social intrínseca, necessariamente envolvem o contato com a população e lidam com problemas diretamente relacionados à saúde pública. Então há uma gama de perspectivas a ser considerada. As atividades de MAC, embora não tenham implicações menos sociais ou menos efeitos políticos, remetem a uma dimensão estritamente médica, ou melhor, do ato médico-hospitalar, quando não, da doença: a cirurgia, o medicamento, a terapia, a radioterapia, a vacinação, o antígeno, o exame diagnóstico, o transplante, e assim por diante. $O$ ato médico, a intervenção hospitalar ou o evento mórbido encontram uma estrutura já estabelecida, consolidada para sua realização. Quando se destina um montante à determinada ação, o seu emprego, a ação técnica que o consumirá e o tipo de instituição na qual será convertido em ação estão, na essência, predeter- 
minados. Não é uma regra inquestionável, mas é o resultado de um determinado modelo de estruturação da assistência. Por exemplo, ao se destinar recursos à cirurgia de varizes, uma série de medidas, como campanha de divulgação, existência de profissionais, espaço especializado para a realização do ato, organização do evento, organização da demanda, terão de ser tomadas pelo gestor, mas ao final o recurso será consumido no ato cirúrgico. Este constitui a destinação final do recurso. As ações de Atenção Básica também se concretizarão, ao final, em ações e serviços. Mas quais ações e quais serviços não estão "definitivamente" determinados ou consensuados? Os recursos destinados a PSF, por exemplo, de início, passam pela discussão "Qual PSF?".

Como argumentamos há pouco, as atribuições - formalmente estabelecidas pelas NOBs - dos entes federativos no sistema de saúde acabam por perder importância na discussão da qualidade das relações federativas. Mais importante se revela o grau de participação dos entes na elaboração das regras de repasse, ou seja, nos fatores condicionantes para a transferência dos recursos. Se houve participação autônoma - o que é pouco provável - as regras são fatores de autolimitação; pactuadas, entretanto. Se não participaram da elaboração, no sentido pleno de autonomia, as regras mais uma vez se mostram puramente instrumento de indução.

Mas é exatamente isso que transforma o momento de pactuação nas CIBs no espaço de esclarecimento possivel do nível de autonomia dos entes subnacionais. Não sendo claras as atribuições das partes (Levcovitz et al., 2001); não tendo participado da elaboração das regras de transferência; submetidos a um modelo de atenção médico-hospitalar preexistente; tendo $60 \%$ dos repasses destinados a ações não-básicas; implantando em seus territórios programas de Atenção Básica criados em jurisdições exógenas e sendo objeto de indução unilateral de um patamar mínimo de serviços a configurar o sistema em âmbito nacional, resta verificar o comportamento dos gestores no momento de pactuação.

Através das atas da CIB-SP, observamos que boa parte das discussões diz respeito ao financiamento das ações; que há um descontentamento geral pelo represamento do teto financeiro; que, nesses limites, há sempre uma disposição à negociação e ao consenso; que as relações entre os entes não se pautam pela subserviência ou hierarquização; que os conflitos emergem com a mesma facilidade que se procura solucioná-los; que a solução dos conflitos, salvo exceções, sempre se encaminham por canais institucionais internos à Comissão; que os participantes formulam propostas de âmbito federal; que os três entes envolvidos recorrem a parcerias de duplas quando o canal institucional não é suficiente para evitar ou resolver o impasse. Diante desse quadro é razoável afirmar que os entes se portam de maneira autônoma na disputa dos recursos e na indução conjunta de um modelo de atenção, participando das discussões nacionais. 
A CIB, como espaço de interlocução entre gestores, apresenta elevado grau de institucionalização dos conflitos; contribui para a elaboração das regras de partilha; interfere na definição do modelo de atenção; intervém na distribuição de recursos mediante procedimentos de pactuação e tem procurado com insistência soluções para a regionalização da atenção, o que significa compartilhamento de atribuições. Esses mecanismos de relacionamento evidenciam os principais componentes do que identificamos como federalismo cooperativo anteriormente. Se a limitação de recursos coloca necessidades intransponíveis no atual marco de financiamento do sistema, a qualidade autônoma das relações entre os gestores, demonstrada na CIB-SP, revela capacidade de influenciar as relações federativas no País, através da busca pactuada dos conflitos.

\section{QUADRO 1 - TRANSFERÊNCIAS DA UNIÃO DESTINADAS À ASSISTÊNCIA HOSPITALAR E AMBULATORIAL (POR PERIODO DE COMPETÊNCIA), EM MILHÕES DE REAIS, EFETIVADAS AOS MUNICÍPIOS DO ESTADO DE SÃO PAULO E AO ESTADO DE SÃO PAULO, SEGUNDO AS RUBRICAS DE REPASSE, 2000 E 2001}

\begin{tabular}{|c|c|c|c|c|c|}
\hline \multirow[t]{2}{*}{ Rubrica de Repasse } & \multicolumn{2}{|c|}{$\begin{array}{l}\text { Estado de São } \\
\text { Paulo e } \\
\text { Municíplos do } \\
\text { Estado de São } \\
\text { Paulo }\end{array}$} & \multirow[t]{2}{*}{\begin{tabular}{|c|}
$\begin{array}{c}\text { Class. } \\
\text { Volume } \\
\text { de } \\
\text { Recursos } \\
\text { (b) }\end{array}$ \\
\end{tabular}} & \multirow[t]{2}{*}{$\begin{array}{c}\text { Compt. } \\
\text { Recursos } \\
2000 \\
\text { a } 2001 \\
\text { (c) }\end{array}$} & \multirow[t]{2}{*}{ 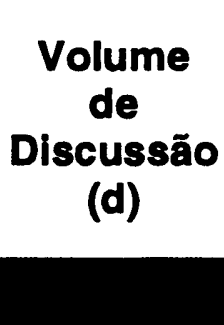 } \\
\hline & 2000 & $2001(a)$ & & & \\
\hline (FAEC) Radioterapia ${ }^{(")}$ & 0,00 & 3,07 & $B$ & $N$ & $N$ \\
\hline Cirurgia Catarata & 1,96 & 2,17 & $B$ & A & $\mathbf{N}$ \\
\hline Transplantes & 1,05 & 0,74 & B & D & $\mathbf{N}$ \\
\hline Cirurgia Oncológica & 1,45 & 0,74 & B & D & $\mathbf{N}$ \\
\hline Cirurgia Varizes & 0,33 & 0,41 & B & $A$ & $\mathbf{N}$ \\
\hline Cirurgia Próstata & 0,19 & 0,40 & B & A & $N$ \\
\hline Prog. Tuberculose & 0,74 & 0,34 & B & D & $\mathbf{N}$ \\
\hline Cirurgia Cardiovascular & 0,00 & 0,25 & B & $A$ & $\mathbf{N}$ \\
\hline (FAEC) Quimioterapia ${ }^{(*)}$ & 0,00 & 0,16 & $B$ & $N$ & $N$ \\
\hline $\begin{array}{l}\text { Incentivo (MAC) Pop. } \\
\text { Indígena }\end{array}$ & 0,00 & 0,12 & B & N & $N$ \\
\hline Antígeno HLA & 0,11 & 0,08 & B & D & $\mathrm{N}$ \\
\hline Retinopatia Diabética & 0,12 & 0,07 & B & D & $\mathrm{N}$ \\
\hline $\begin{array}{l}\text { Cirurgia Deform. Crânio- } \\
\text { facial }\end{array}$ & 0,04 & 0,02 & B & D & $\mathbf{N}$ \\
\hline
\end{tabular}




\begin{tabular}{|c|c|c|c|c|c|}
\hline \multirow[t]{2}{*}{ Rubrica de Repasse } & \multicolumn{2}{|c|}{$\begin{array}{l}\text { Estado de São } \\
\text { Paulo e } \\
\text { Municípios do } \\
\text { Estado de São } \\
\text { Paulo }\end{array}$} & \multirow{2}{*}{\begin{tabular}{|c|}
$\begin{array}{c}\text { Class. } \\
\text { Volume } \\
\text { de } \\
\text { Recursos } \\
\text { (b) }\end{array}$ \\
\end{tabular}} & \multirow[t]{2}{*}{\begin{tabular}{|c|} 
Compt. \\
Recursos \\
2000 \\
a 2001 \\
(c)
\end{tabular}} & \multirow[t]{2}{*}{ 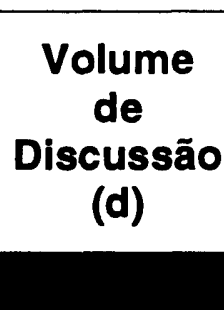 } \\
\hline & 2000 & $2001(a)$ & & & \\
\hline $\begin{array}{l}\text { Camp. Acomp. Pós- } \\
\text { transplantes }\end{array}$ & 0,00 & 0,02 & B & $N$ & $\mathrm{~N}$ \\
\hline Campanha de pré-natal & 0,00 & 0,01 & B & $\mathbf{N}$ & $\mathbf{N}$ \\
\hline $\begin{array}{l}\text { Co-financ./Custeio U. } \\
\text { Próprias }\end{array}$ & 0,00 & 0,00 & $B$ & - & $\mathbf{N}$ \\
\hline Pré-natal e Nascimento & 0,00 & 0,00 & B & - & $\mathrm{N}$ \\
\hline $\begin{array}{l}\text { (FAEC) Radioterapia/ } \\
\text { Quimioterapia }\end{array}$ & 0,50 & 0,00 & $B$ & D & $\mathrm{N}$ \\
\hline Cirurgia Hérnia & 0,00 & 0,00 & $B$ & - & $\mathbf{N}$ \\
\hline Medicam. Transplantes & 0,00 & 0,00 & B & - & $\mathrm{N}$ \\
\hline Assistência a Calamidade & 0,00 & 0,00 & $B$ & - & $\mathrm{N}$ \\
\hline Epilepsia & 0,00 & 0,00 & B & - & $\mathrm{N}$ \\
\hline Terapia Renal Substitutiva & 0,05 & 0,00 & $B$ & D & $\mathrm{N}$ \\
\hline Medicam. Excepcionais & 118,54 & 114,97 & $E$ & D & $\mathrm{NE}$ \\
\hline $\begin{array}{l}\text { Prog. Combate Cåncer } \\
\text { Colo Uterino }\end{array}$ & 2,74 & 1,72 & B & D & SI \\
\hline Vacinação & 0,00 & 1,29 & B & A & SI \\
\hline Vacinação Anti-rábica & 1,14 & 1,13 & B & $\mathrm{D}$ & SI \\
\hline Impacto Psiquiatria & 0,00 & 0,54 & B & $\mathbf{N}$ & SI \\
\hline $\begin{array}{l}\text { Cadast. Aval. Estabel. } \\
\text { Saúde }\end{array}$ & 0,00 & 0,09 & B & $\mathbf{N}$ & SI \\
\hline (FAEC) Ações Estratégicas & 0,00 & 12,47 & $M$ & $\mathrm{~N}$ & SM \\
\hline $\begin{array}{l}\text { Assistência Hospit. e } \\
\text { Ambulat. (MAC) }\end{array}$ & 659,62 & 302,81 & $E$ & A & SP \\
\hline Ass. H. A. (Média Complex.) & 0,00 & 300,65 & $E$ & $\bar{A}$ & SP \\
\hline Ass. H. A. (Alta Complex.) & 0,00 & 70,60 & $E$ & $\bar{A}$ & SP \\
\hline $\begin{array}{l}\text { Co-financ. Carga Viral } \\
\text { TCD } 4 / C D 8\end{array}$ & 0,00 & 5,41 & B & $\mathrm{N}$ & SP \\
\hline MAC Vigil. Sanitária & 2,24 & 3,18 & B & A & SP \\
\hline \begin{tabular}{|l|} 
(FAEC) Câmara de \\
Compensação \\
\end{tabular} & 0,42 & 0,00 & B & $\bar{D}$ & $\overline{S P}$ \\
\hline Ass. Hosp. e Ambul. (MAC) & 791,24 & 823,46 & & & \\
\hline
\end{tabular}

Fonte: Datasus

(a) Não inclui valores referentes ao mês de dezembro de 2001.

(b) Classificação dos repasses em termos do volume de recursos. Legenda: B - baixo; E - eleva-

do; $M$ - médio.

(c) Variação do volume de recursos entre os anos de 2000 e 2001. Legenda: A - aumenta; D diminui; $\mathrm{N}$ - recursos novos em 2001; "—" mantém em zero. 
(d) Classificação dos temas segundo a quantidade de vezes que figurou como ponto de pauta nas reuniões e segundo o volume de discussão ocorrido. Legenda: SP - pouca discussão; SI - sim, referente a recursos não elevados; SM - sim, referente a recursos médios; $N$ - não houve discussão; NE - não, recursos médios.

(") Assunto tratado juntamente com a rubrica "Açð̄es Estratégicas".

\section{QUADRO 2 - TRANSFERÊNCIAS DA UNIÃO DESTINADAS À ATENÇÃO BÁSICA (POR PERIOODO DE COMPETÊNCIA),} EM MILHÕES DE REAIS, EFETIVADAS AOS MUNICÍPIOS DO ESTADO DE SÃO PAULO E AO ESTADO DE SÃO PAULO, SEGUNDO AS RUBRICAS DE REPASSE, 2000 E 2001

\begin{tabular}{|c|c|c|c|c|c|}
\hline \multirow[t]{2}{*}{ Rubrica de Repasse } & \multicolumn{2}{|c|}{$\begin{array}{c}\text { Estado de São } \\
\text { Paulo e } \\
\text { Municíplos do } \\
\text { Estado de São } \\
\text { Paulo }\end{array}$} & \multirow[t]{2}{*}{\begin{tabular}{|c|}
$\begin{array}{c}\text { Class. } \\
\text { Volume } \\
\text { de } \\
\text { Recursos } \\
\text { (b) }\end{array}$ \\
\end{tabular}} & \multirow[t]{2}{*}{\begin{tabular}{|c|} 
Compt. \\
Recursos \\
$2000 \mathrm{a}$ \\
2001 \\
(c)
\end{tabular}} & \multirow[t]{2}{*}{$\begin{array}{l}\text { Volume } \\
\text { de } \\
\text { Discussão } \\
\text { (d) }\end{array}$} \\
\hline & 2000 & 2001 (a) & & & \\
\hline Vacinação Poliomielite & 0,00 & 0,96 & B & $\mathbf{N}$ & $\mathbf{N}$ \\
\hline Descentralização FUNASA & 0,00 & 0,00 & B & 一 & $\mathbf{N}$ \\
\hline $\begin{array}{l}\text { Assistência à População } \\
\text { Indígena }\end{array}$ & 0,00 & 0,00 & B & - & $\mathbf{N}$ \\
\hline $\begin{array}{l}\text { Programa de Atenção Básica } \\
\text { (fixo) }\end{array}$ & 371,62 & 331,09 & E & D & S \\
\hline $\begin{array}{l}\text { Epidemiologia e Controle de } \\
\text { Doenças }\end{array}$ & 49,82 & 70,83 & E & A & $S$ \\
\hline $\begin{array}{l}\text { Prog. Saúde da Família - } \\
\text { Municípios }\end{array}$ & 25,52 & 39,76 & $\mathbf{E}$ & A & S \\
\hline Farmácia Básica - Estados & 35,82 & 33,54 & E & D & 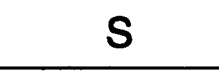 \\
\hline $\begin{array}{l}\text { Prog. Ag. Comunit. Saúde - } \\
\text { Municípios }\end{array}$ & 10,77 & 16,68 & M & A & $S$ \\
\hline $\begin{array}{l}\text { Prog. Combate Carências } \\
\text { Nutricionais }\end{array}$ & 9,31 & 8,96 & M & D & $\mathbf{s}$ \\
\hline Programa Vigilância Sanitária & 6,31 & 7,95 & M & A & $\mathbf{s}$ \\
\hline $\begin{array}{l}\text { Medicamento de Saúde } \\
\text { Mental }\end{array}$ & 4,44 & 4,44 & B & $\mathbf{M}$ & s \\
\hline $\begin{array}{l}\text { Cadastro Nacional Usuários } \\
\text { SUS }\end{array}$ & 0,00 & 1,69 & B & N & $S$ \\
\hline Incentivo Saúde Bucal & 0,00 & 1,03 & B & $\mathrm{N}$ & 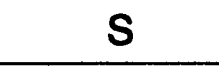 \\
\hline $\begin{array}{l}\text { Programa Saúde da Família } \\
\text { - Estados }\end{array}$ & 4,32 & 0,98 & B & D & S \\
\hline
\end{tabular}




\begin{tabular}{|c|c|c|c|c|c|}
\hline \multirow[t]{2}{*}{ Rubrica de Repasse } & \multicolumn{2}{|c|}{$\begin{array}{c}\text { Estado de São } \\
\text { Paulo e } \\
\text { Municípios do } \\
\text { Estado de São } \\
\text { Paulo }\end{array}$} & \multirow[t]{2}{*}{\begin{tabular}{|} 
Class. \\
Volume \\
de \\
Recursos \\
(b)
\end{tabular}} & \multirow[t]{2}{*}{$\begin{array}{l}\text { Compt. } \\
\text { Recursos } \\
2000 \text { a } \\
2001 \\
\text { (c) }\end{array}$} & \multirow[t]{2}{*}{$\begin{array}{c}\text { Volume } \\
\text { de } \\
\text { Discussão } \\
\text { (d) }\end{array}$} \\
\hline & 2000 & $2001(a)$ & & & \\
\hline $\begin{array}{l}\text { Prog. Agentes Comunit. } \\
\text { Saúde - Estados }\end{array}$ & 1,05 & 0,31 & B & D & $S$ \\
\hline Outros & 0,00 & 0,01 & B & $\mathrm{N}$ & $S$ \\
\hline $\begin{array}{l}\text { Farmácia Básica - } \\
\text { Municípios }\end{array}$ & 0,00 & 0,00 & B & - & $S$ \\
\hline ATENÇÃO BÁSICA & 518,98 & 518,23 & & & \\
\hline
\end{tabular}

Fonte: Datasus

(a) Não inclui valores referentes ao mês de dezembro de 2001.

(b) Classificação dos repasses em termos do volume de recursos. Legenda: $B$ - baixo; $E$ - elevado; $M$ - médio.

(c) Variação do volume de recursos entre os anos de 2000 e 2001. Legenda: A - aumenta; D diminui; $\mathrm{N}$ - recursos novos em 2001; "—" mantém em zero.

(d) Classificação dos temas segundo a quantidade de vezes que figurou como ponto de pauta nas reuniões e segundo o volume de discussão ocorrido. Legenda: S - sim, houve discussão; N - não houve discussão.

\section{BIBLIOGRAFIA}

ALMEIDA, M. H. T. "Federalismo e Políticas Sociais". Revista Brasileira de Ciências Sociais, 10(28):88-108, 1995.

BAPTISTA, T. W. F. "Seguridade Social no Brasil". Revista do Serviço Público, ano 49, n. 3, pp. 101-120, jul.-set. de 1998.

BARROSO, L. R. Direito constitucional brasileiro: o problema da federação. Rio de Janeiro: Forense, 1982.

. BRASIL (1990). Lei n. 8.080/90.

. BRASIL (1990). Lei n. 8.142/90.

. BRASIL (2000). Constituição da República Federativa do Brasil: promulgada em 5 de outubro de 1988. São Paulo: Saraiva.

CHIORO, A.; ALMEIDA, E. S. \& ZIONI, F. Políticas públicas e organização do sistema de saúde. Antecedentes, reforma sanitária e o SUS. Faculdade de Saúde Pública. Programa de pós-graduação, outubro de 1997. (mimeo) 
COHN, A. "A saúde na previdência social e na seguridade social: antigos estigmas e novos desafios". In: COHN, A. \& ELIAS, P. E. M. Saúde no Brasil. São Paulo: Cortez-Cedec, 1997.

DALLARI, S. G. "Descentralização versus municipalização". Saúde em Debate, n. 35, pp. 39-42, 1992.

ELAZAR, D. Exploring federalism. Tuscaloosa: University of Alabama Press, 1987.

ESCOREL, S. Reviravolta na saúde. Origem e articulação do movimento sanitário. Rio de Janeiro: Fiocruz, 1998.

HEIMANN, L. S.; CARVALHEIRO, J. R.; DONATO, A. F.; IBANHES, L. C.; LOBO, E. F. \& PESSOTO, U. C. O Município e a Saúde. São Paulo: Hucitec, 1992.

HORTA, R. M. "As novas tendências do federalismo e seus reflexos na Constituição Brasileira de 1988". Revista do Legislativo, ALEMG, n. 25, jan./mar. de 1999.

KUGELMAS, E. \& SOLA, L. "Recentralização/Descentralização: dinâmica do regime federativo no Brasil dos anos 90". Tempo Social. Rev. Soc. USP. São Paulo, 11(2): 63-81, outubro de 1999.

LEVCOVITZ, E.; LIMA, L. D. \& MACHADO, C. V. "Política de Saúde nos anos 90: relações intergovernamentais e o papel das Normas Operacionais Básicas". Ciência \& Saúde Coletiva, 6(2): 269-291, 2001.

MEDICI, A. La asistencia sanitaria en el federalismo brasileño. Banco Interamericano de Desarrollo, septiembre de 2001 (Borrador).

MERHY, E. E. \& BUENO, W. S. "Organizações sociais: autonomia de quem e para que?" Documento disponível no site Conferência Nacional de Saúde On-line (http://www.datasus.gov.br/cns).

MINISTÉRIO DA SAÚDE, BRASIL (1993). NOB 01/93.

MINISTÉRIO DA SAÚDE, BRASIL (1997). NOB 01/96.

MINISTÉRIO DA SAÚDE, BRASIL (2001). NOAS-SUS 01/2001.

NASCIMENTO, V. B. SUS, Gestão pública de Saúde e sistema federativo no Brasil. São Paulo: Faculdade de Medicina da Universidade de São Paulo (Tese de Doutorado), 2000.

NASCIMENTO, P. R. SUS - Instâncias de negociação entre os gestores: as comissões intergestores e a questão federativa. São Paulo: Faculdade de Saúde Pública - USP (Dissertação de Mestrado), 2002.

ROVIRA, E. A. Federalismo y cooperacion en la Republica Federal Alemana. Madri: Centro de Estudios Constitucionales, 1986. 